\title{
Xiangqin Wave: A Close Look at Modern Chinese Dating Culture
}

\author{
Jing Zheng \\ The University of Hong Kong \\ Email: zhengj@hku.hk
}

\section{Doi:10.5901/ajis.2013.v2n9p319}

\begin{abstract}
This is an empirical study of how conventional practice of Xiangqin (matchmaking) revives and forms a specific dating culture in modern China. Individuals' concrete experience of participating in various new forms of Xiangqin (i.e. commercial matchmaking websites and offline fairs, high-end matchmaking clubs, marriage-hunting services, matchmaking TV shows) are investigated. Through the perspective of commodification of intimacy and gender politics, the study argues that modern Chinese dating culture are symbolically and practically shaped by the commercial society. Apparently, the intersection between economics and people's intimate interactions perpetuates class divisions in current China. The commercialization of Xiangqin also reinforces gender stereotypes. Nevertheless, it also contributes to women empowerment at the same time. A dating culture penetrated by market value creates conditions for women's increased sense of autonomy, greater control over intimate relationship, and equality between the sexes.
\end{abstract}

\section{Introduction}

In mainland China, the term "Xiangqin" (matchmaking) has been overwhelming during these years (Jing, 2011). The numerous media reports, the rapidly-growing matchmaking industry (Li, 2011), the high-rating matchmaking reality TV shows (Li \& Liu, 2011), and the crowed parents' corners in parks in many Chinese cities (Zhao, 2010) all indicate that almost every Chinese people are involved in a Xiangqin wave. As a traditional Chinese courtship practice which has more than 1000 years of history ${ }^{1}$, Xiangqin comes back in modern Chinese life and becomes popular in many cities ${ }^{2}$. Chinese heated issues of Xiangqin has also received world-wide attention with news like the indigenous commercial matchmaking website Zhenai.com has already become the world's largest matchmaking website by number of registered members ${ }^{3}$. Although the convention form of Xiangqin (i.e. a one-to-one arranged date) still exists and is accepted by some people, under the circumstance of market economy, many new forms Xiangqin emerge (i.e. commercial matchmaking websites and offline fairs, high-end matchmaking clubs, marriage-hunting services, matchmaking TV shows) and become popular among single individuals. This phenomenon gives rise to a specific dating culture within the context of Chinese modernization.

\section{Literature review}

This study draws on theory of commodification of intimacy to understand modern Chinese dating culture reflected through the above-mentioned Xiangqin wave in China. The concept of commodification of intimacy has its roots in economic sociology, which challenges the traditional sociological distinction between money and intimacy as two separate spheres. As Millman (1991: 4) put forwards, in a market economy, money 'insinuates itself into even the most intimate setting'. Along the same line, Zelizer also argues that 'the logic of the marketplace has increasingly penetrated our most intimate social relations of family and community' (Zelizer, 1997: 215). According to her, people 'all use economic activity to create, maintain, and renegotiate important ties - especially intimate ties - to other people' (Zalizer, 2005). Likewise, Illouz (2007) rejects the dichotomy of economics and intimacy, arguing that in current society, "economic relations have become deeply emotional, while close, intimate relationships have become increasingly defined by economic and political models of bargaining, exchange, and equity". Extended from these early works, Constable (2009) mentions that "intimate

\footnotetext{
${ }^{1}$ Source from http://traditions.cultural-china.com/en/14Traditions7663.html

2 Source from http://www.tourochina.com/newsarea/308/Love-in-Tradition

3 Source from: http://www.reuters.com/article/2009/09/08/idUS115781+08-Sep-2009+BW20090908
} 
and personal relations become increasingly and more explicitly commodified" in modern society. She gives a more detailed argument about commodification of intimacy, which refers to "the ways in which intimacy or intimate relations can be treated, understood, or thought of as if they have entered the market: are bought or sold; packaged and advertised; fetishized, commercialized, or objectified; consumed or assigned values and prices; and linked in many cases to transnational mobility and migration, echoing a global capitalist flow of goods" (Constable, 2009).

Specifically, academics have noted the relevance of economic theories to the understanding of dating and partner selection for a long time. Scholars in various fields have utilized economic-based models as analytical frameworks to study relationship initiation and to explain people's overall partner selection behavior (e.g. Becker, 1973; Bernard, et al., 1991; Edwards, 1969; Hirschman, 1987; Takeuchi, 2006). There are also a few existing studies which contextualize people's partner selection in a commercialized and efficiency-oriented dating culture given rise by contemporary consumer society (e.g. Ahuvia \& Adelman, 1993; Coupland, 1996; Jagger, 1998, 2001; Heino, et al., 2010; Li, 2011). These literatures provide us important perspectives to understand how individuals draw on cultural resources provided by commercial society to create and maintain intimate relationships with others. However, I hold that equal emphasis should also be put on how certain social, cultural, economic values are coded and staged through individual's practices of intimacy in a consumer society. In the present study, I would look beyond the influence of market economy and invites other factors such as gender, class, and cultural context in the analysis of women's lived experience of participating in Chinese current Xiangqin wave.

\section{Methodology}

Situated in Guangzhou, a southern Chinese city where China's economic opening-up was first implemented and influence of commercial culture is omnipresent, the study is based on in-depth interviews with 36 women aged from 24 to 38. Their concrete experience of participating in various newly emerged forms of Xiangqin in contemporary China is investigated. Through the perspective of commodification of intimacy and gender politics, the study looks into how commercial society shapes modern Chinese dating culture and creates conditions for the rising of new Chinese femininity.

\section{Findings and analysis}

\subsection{Partner selection as a shopping experience: what are the options?}

Since its inception in mid-1990s, dating websites have rapidly increased in popularity around the world (Callsen, 2013). The advent of the Internet has led to a sizeable increase in the number of options from which one can choose as potential mates (Lenton, et al., 2010). Technical advancement facilitates people's interaction, providing possibilities to expand one's social network and the pool of eligible with low cost and high efficiency.

The situation in China is no exception. However, instead of 'dating website', both Chinese users and service companies often use the term 'matchmaking website' (Xiang qin wang zhan) or 'website for love and marriage' (Hun lian wang zhan) which seems to imply a more serious attitude and greater legitimacy. The earliest Chinese matchmaking website, zhenai.com, was found in $1998^{4}$. In contemporary China, according to statistics ${ }^{5}$, zhenai.com, jiayuan.com, marry5.com, and baihe.com are the mainstream matchmaking websites in terms of number of registered members, market share, and number of page views. All of them are commercial websites with their own revenue models ${ }^{6}$ such as offering free search but charging users to communicate, categorizing users according to membership fees and enabling them to use relevant advance features of the website, and providing customized matchmaking services. The cost for using basic features like sending and receiving emails ranges from 198 yuan to 499 yuan per year ${ }^{7}$. Among these mainstream websites, zhenai.com only provides one-to-one matchmaking service; the cost of online service is 3999 yuan for four months ${ }^{8}$ (offline customized matchmaking belongs to marriage hunting service, which is discussed in later section).

\footnotetext{
${ }^{4}$ Source from : http://wenku.baidu.com/view/7883618c6529647d2728528b.html?from_page=view\&from_mod=download

${ }^{5}$ Source from: http://wenku.baidu.com/view/212bf719650e52ea55189877.html

${ }^{6}$ Source from: http://wenku.baidu.com/view/7883618c6529647d2728528b.html?from_page=view\&from_mod=download

${ }^{7}$ Source from: http://www.jiayuan.com/usercp/service/servicenew.php and http://payment.baihe.com/product/index_together_new.jsp

${ }^{8}$ Source from: http://profile.zhenai.com/lovestory/indexhnznone.jsps
} 
Derived from online services provided by matchmaking websites, currently there are many newly emerged forms of matchmaking activities such as commercial matchmaking fairs, marriage hunting services, high-end matchmaking clubs, and matchmaking TV shows. Most of these activities are organized or co-organized by the above-mentioned mainstream matchmaking websites.

Matchmaking fairs are offline activities held by major commercial matchmaking websites such as zhenai.com and jiayuan.com for its registered members. Most of these fairs are held in big cities; they take various forms and attract a large number of participants. Li, former host of matchmaking fairs provided by jiayuan.com, introduces:

Jiayuan.com has four branches in China. Beijing branch is in charge of (activities in) northern China, Shanghai branch eastern China, Chengdu western China, and Guangzhou southern China. In these four major cities, we hold matchmaking fairs twice a month; for other cities, such as Ganzhou (a city in Jiangxi province), one in every two months. All these fairs are organized for members of our websites and we charge them entrance fee every time. There're at least 120 or 130 participants in every fair; sometime there're around 700 people. Activities are in various forms. The simplest one is gathering in a banquet hall; the host leads people to play some games. Sometime we organize karaoke, buffet, cocktail party, excursion, hiking, picnic, self-driving tour, horse-riding, etc.

Despite a wealth of activities and the maximized possibilities of meeting 'the one' brought by them, some people complain that the quality of pool of eligible are impaired by the large amount of participants. Several interviewees even reject to attend such activities because they simply do not believe they could find a suitable partner among a sea of faces. For example:

The first fair I went to should be the most low-level one. The fair was held in a new estate; maybe it's also for the new estate's advertisement or something, so we didn't need to pay the participation fee. Because it's free, there're so many people. Many men in that fair didn't look decent. Some wore creased clothes; some wore suits, but their suits were either too big or too small; some carried awkward-looking bags. I realized right away that I couldn't find my ideal partner in such activities. (Wei Wei, 28)

Many men who attend such fairs didn't have good manner, let alone a good economic background. Let me give you a simple example. I once attended a fair like this; there're a lot of people, around 200. Then I saw some men always complained; they were picky about everything: the air-con wasn't strong enough, the food wasn't tasty, there weren't enough drinks, ladies in the fair weren't attractive, staffs weren't attentive, so and so forth. I think tolerance and good manners should be the basic characteristics for a man. (May, 25)

I've never attended those fairs. Every time there's a poster for such fair on the website, I would take a look at it. You could click into the registered participants' personal page and see who's attending the fair. Most of them have photos in their pages. I often found that there're much more women than men participants. There're already not enough men; then when I looked at those men's photos, aiya! Most of them looked like pigs. Thus I know it's impossible for me to find someone on those fairs. (Shan, 30)

No, I won't attend (matchmaking fairs). There're so many people there; you don't know all of them at all. How can you find someone among a sea of people? (Huochai, 26)

In respond to feedbacks and demands like these, high-end matchmaking clubs and marriage hunting services are initiated. Messages of these advanced services are usually posted on the front page of major matchmaking websites with eye-catching headlines and pictures. Zhang, a matchmaker who used to work for jiayuan's 'elite club', further introduces members and fees for such advanced service:

The 'elite club' is established for single people with decent background. There're 50 men and 50 women in the club. Quality of these members is not bad; after all, they need to pay certain amount of membership fee. There're three categories of fee: 1000 yuan for a trail club activity; 2000 yuan for two activities; 5000 yuan for a year's activities.

Besides high-end and small-scale social gatherings, organizers also provide customized marriage hunting service for an even smaller group of people. Many of these customers will attend the high-end parties; some of them require strict confidentiality of their personal information, and they only accept one-to-one arranged meetings. Without doubt, the cost and threshold are much higher:

The cost of (zhenai.com's) offline customized service, the minimum is 30,000 for half a year. For similar service of jiayuan.com, in the past it's 30,000; now is 40,000. (Zhang, former matchmaker of jiayuan.com, currently works as a marriage consultant specialized for marriage hunting service in zhenai.com)

There's threshold for our club. The fee for male member is 200,000 yuan a year. We'll organize four high-end activities for them. They can attend the first one for free; for the rest three ones, they also need to pay some money. (Li, former host of jiayuan's matchmaking fairs, currently works as manager of China Entrepreneur Club for Singles) 
Matchmaking TV shows such as 'If You Are the One' (非诚勿扰, Fei cheng wu rao), 'Let's Date' (我们约会吧, Wo men yue hui ba), and 'One in One Hundred' (百里挑一, Bai li tiao yi) have emerged in recent years and become extremely popular in China. Take the most well-known one, 'If You Are the One' which began airing since 2010 in Jiangsu Satellite Television, as an example, it received about 10,000 applications during the first month since it operated. And within two months, its audience rating has rocketed to the top (Li, 2011); news even suggest that with some 50 million watching every episode, the rating of this program once seconded only to the China Central Television's evening news broadcast Xinwen Lianbo ${ }^{9}$. Cooperation with mainstream matchmaking websites such as zhenai.com, jiayuan.com, and baihe.com is the major way for these TV shows to recruit participants. When browsing the front pages of these websites, one can easily find relevant sections which lead to applying for different matchmaking TV shows. Information posted in such sections also indicates that the whole interview and selection process in several major cities for participant recruitment is organized by companies of these matchmaking websites. When the TV show is broadcasted, the host emphasizes clearly which candidate is recommended by which matchmaking website as well. Therefore, the influence of matchmaking websites on almost all later emerged form of Xiangqin is very conspicuous.

\subsection{Market values embedded in Xiangqin}

Influence of commercial society and market value are apparent in the current study on Xiangqin in contemporary China. The level of a matchmaking service and relevant activities it includes are graded by money. The use of economic metaphors are quite frequent in both service providers' and customers' descriptions of relevant issue.

There are different kinds of Xiangqin activities...The level is determined by the fees...Different activities require different thresholds. This is about market. (Li, former host of jiayuan's matchmaking fairs, currently works as manager of China Entrepreneur Club for Singles)

In fact, many people are willing to join the 'elite club'. After all, thresholds of entering the club can guarantee something (Zhang, former matchmaker of jiayuan.com)

I'll check my mailbox (of matchmaking websites) every now and then. Actually I'm not very hopeful; just want to have an idea about the (marriage) market and what kinds of people are on the market. (Shan, 30)

Ai, all those (matchmaking) websites are money-oriented, right? But if I'm still single at the end of this year, l'll have a try. (Yo Yo, 29)

Many interviewees also have the assumption and observation that the more a service costs, they better quality it will guarantee. Some of them even emphasize that they do not want to waste their time on free-of-charge or inexpensive matchmaking services and activities. Rather, they are willing to pay more in exchange of a better pool of eligible.

I've been to many matchmaking fairs; the fees ranged from 200 yuan to 400 yuan. Overall, the more it costs, the better quality of participants. (Lan, 29)

I never trust those activities (which are free of charge). Those male participants are not good. Most of them are poor-looking, like migrant workers, right? ...... I would rather spend some money on this. The high-end club charges 3000 yuan for half a year, not expensive. They can introduce more reliable men. (Shuang, 32)

There are also cases that interviewee even bluntly describe partner selection as an exchange of men's economic resources for the women's youth and attractiveness. This is an instance showing that market value has penetrated in mating ideology nowadays, and people can openly articulate it without feeling ashamed.

I don't want to deny that these (marriage hunting service) are for the matchmaking of rich men and beautiful women, but I think people should look at this from a more objective perspective. I can afford an Audi car, why bother to select among a bunch of Alto cars? ...Women are the same. I'm young, beautiful, good-educated, and have fair skin; why can't I marry a rich and handsome guy instead of a poor loser? Who doesn't want a better life? It's like you go to the market and you'll see big and juicy fruits always cost more, don't they? (May, 25)

Most interviewees indicate that the major function of matchmaking websites and other forms of Xiangqin in China is to increase the number of options from which one can choose and facilitate the initial stage of partner selection. Therefore, after this stage, they often go out for a one-to-one date with a potential partner for further consideration. Through their articulation of these dating interactions with a potential male partner, the message that 'money is a crucial criterion for decision-making' is very clear in some cases.

\footnotetext{
${ }^{9}$ Source from: http://en.wikipedia.org/wiki/Fei_Cheng_Wu_Rao
} 
I don't like stingy men. Normally I don't spend men's money; I'm economically independence. But there're some men who are penny-pinching even on the meal on our first date. It's really difficult for me to accept this... For example, when we looked at the menu and I said it's ok. They would say 'ok?' 'You think this is inexpensive?' or you can tell how they think from their facial expression... This means that I don't worth their investment. Then please go away. Don't waste my time. (Misu, 29)

Of course men should pay the bill! It's an axiom, isn't it? Some of my female friends even said that if the guy proposed to go Dutch during a date, they would badmouth him and never date him again. (Emily, 30)

I don't think any Chinese woman would accept a stingy man. It's very difficult for that kind of man to find a wife. (Cheng, 31)

Nowadays many men are very pragmatic. I used to date some men who even used coupon and brought me to very lousy place for dining. That's so unromantic, so mean...... (Shuang, 32)

\subsection{Reinforced gender stereotypes in commodification of Xiangqin}

Another observation of the study is that in commercialized forms of Xiangqin, gender stereotypes are reinforced. Influence of traditional gender norms and mating ideology such as 'men are valued for their economic status and women are valued for their appearance' (Nan cai nv mao) and men should take the initiative in courtship are still obvious. Such influence is reflected in established rules in established and/or unspoken social rules in different forms of matchmaking activities. An explicit example is the higher the level (graded by money consumed) of a matchmaking activity, the less a female participant needs to pay. To attend such activities, the prerequisite for men is wealth; and for women are youth, beautiful appearance, and other characteristics of being a 'good wife'.

There's threshold for our club. The fee for male member is 200,000 yuan a year...Female members don't need to pay the fee, but they all look glamorous. (Li, currently works as manager of China Entrepreneur Club for Singles)

The first date (arranged by marriage hunting service) I went was with a man; he paid a lot, thus the company held an audition specifically for him. And I was the first girl selected by the company to meet him...... In fact, all of these men we met have relatively high social status. They are quite good...... The standard of 'good' is of course economic status. Most of them are businessmen. You can do these things only when you're rich. (Ding Ding, 25, who has been selected for marriage hunting service)

Jiayuan.com has high-end matchmaking club. Their advertisement says all male members in the club have high salary and they are decent in other aspect. Within it there's an 'elite women's club'. (What's that?) Well, frankly speaking it's actually a 'beauties club'. It's like a beauty pageant. There're strict requirements for one's appearance. All those passed the audition are good-looking. (Lan, 29, who once applied for 'elite club' but failed to be accepted)

A more obvious case is how 'elite clubs' and marriage hunting service recruit female members for following matchmaking service for superrich men. Take China Entrepreneur Club for Singles as an example, the threshold for male member is 'president of the board or general manager of large state-owned enterprises or foreign companies; or one whose personal assets exceeds 100 million yuan'10. And the basic membership fee for them is 200,000 yuan per year; for advanced services, the membership fee is 400,000 yuan per year and even higher for more customized service. On its front page, there's a glamorous wedding dress with a clear caption 'Find Cinderella' next to the picture. Under such circumstances, female applicants need to go through many rounds of interviews and inspections in order to be accepted. The requirements for each round are very strict and meticulous. For example, the first round is a cosmetic surgeon examining whether the applicants are 'natural beauties'; the second round is for intellectual and inner quality assessment; the third round is examination of household chores such as cooking and tying a necktie; the fourth round is personality and psychological health test which requires an applicant to finish a questionnaire; the fifth round is a marriage consultant asking the applicant's past relationship experience and examining whether she has a 'correct' ideology about love, marriage, and family; the following rounds are designed for meeting specific requirements mentioned by male customers; an applicant's understanding of charity, her physiognomy, and even whether she is a virgin will be inspected. Li, who currently works as manager of this company, told me they go around China's big cities to look for girls who fit in such requirements. As for the result, 'it's considered a high rate if we can select one girl out of 300 applicants', said Li. Another thing which worth mentioning is that when Li demonstrated information of girls who has been accepted in their club, I noticed that the age range of them is roughly 20 to 25 ; the youngest one is only 18 years old.

\footnotetext{
${ }^{10}$ Source from: http://www.520cecs.com/fronted/cecs.jsp
} 
Besides these, there are other rules of matchmaking activities which comply with gender norms such as men initiating communication and interactions. For instance, in many interactive activities on matchmaking fairs, there are rules requiring women stand in lines and wait for the queue of male participants to shake hands and exchange information cards with them, rules encouraging men go on the stage and confess their love to female participants off stage, rules incenting men to invite female participants to dance or be their partner to play games, etc.

\subsection{New femininities reflected in Xiangqin}

Despite the strengthened gender roles reflected in some situation, the study finds that Xiangqin activities permeated with commercial culture simultaneously create conditions for emergence of new femininities in gender dynamics. Overall, when it comes to partner selection and marriage, modern Chinese women enjoy more autonomy and equality between the sexes.

The plot design in some popular matchmaking TV shows is a good example indicating such social changes regarding women empowerment. In shows like 'If You Are the One', 'Let's Date', and 'One in One Hundred', all of them invite female participants to stand on stage as jury, while male participants have around 20 minutes to demonstrate themselves and see whether they could win an opportunity to date one of the women on stage. Many of these female participants are very active and confident when expressing their opinion; their sharp and critical remark towards the male candidates is also a reason why these shows attract large amount of audiences. Besides TV shows, in matchmaking fairs, women's proactive behaviors in gender interactions are observed as well. Although rules usually encourage men take the initiative, women can take a much more active role in responding to invitations. During my participant observation, I even saw some women who challenged this dating script and made the first move to exchange contact information with men they found desirable. When I ask one interviewee about this, she said:

After all, this is my attitude towards love. They say a girl needs to be restrained and something, but I don't think so. If I really like someone, I'll be proactive. I can't help telling myself 'I've got to have a try. Otherwise when I'm old or when I don't feel happy in my marriage in the future, I would regret..... Some people may think it's shameful for a girl to be so proactive, but I think this is my own business. I don't care how others look at me. (Chang, 26)

Women's appearance and dress when attending matchmaking activities are also indicators of the emerged new femininity in contemporary China. In matchmaking fairs, high-end parties, interviews for marriage hunting service, matchmaking TV shows, and many other relevant occasions, one can easily find that almost all women are dressed up and they dare to show their sexual capital in the process of partner selection. Compared to women's dress code decades ago under Communist revolutionary culture (Ip, 2003), these changes are remarkable.

Another representation of Chinese new femininity is women's open elaboration and celebration of their desires of both a good life and intimacy. In both the traditional and socialist cultures, most of these individual desires were either controlled or stigmatized as improper (Yan, 2010). But nowadays, Chinese people, including Chinese women, dare to express that they aspire to a life of quality. They are willing to consume different commercialized matchmaking activities, and they do not feel ashamed to attend these activities and speak out that socio-economic status is an important concern in their mate choice. Moreover, rather than seeking a 'love for revolution' (Glosser, 2003), many interviewees in this study openly state that they want to find an intimate partner for their own sake; when expressing their mating standard, they frequently bring up the term 'love':

Lots of men woo me, but I won't get married unless I found a man whom I really really love. Otherwise I can't stand marriage life. (Emma, 30)

I have to find someone I love. If the feeling between us fades, I can't control that. But we should love each other in the beginning. Some people talk to me to 'stop being unrealistic and talk about love all the time', etc. But I don't want to settle down in such a careless way. (Liang, 31)

Simultaneously, some interviewees insist that they desire a relationship in which they can enjoy an independent self; they usually actualize this principle through details such as bill payment when going out with a potential mate. Being economic independent also helps them to achieve greater control over intimate relationship. For example:

Marriage is pragmatic. You can't always depend on one person. I'm not able to support a man economically, but I don't him to support me, either. I have my own job. I'm independent. (Le Le, 29)

Usually I would bring up the idea of going Dutch, even if the man didn't accept my money in the end. After all, I think we both benefit from a date, and it's unfair to ask men to pay all the money... In both dating and marriage, I think economic independence is important. If I want something, why can't I buy for myself? If you ask everything from your partner, depend too much on him, you'll be degraded. (Mo Li, 27) 
(I proposed to go Dutch because) I don't want him to have the impression that 'I pay the bill, why don't you agree to be my girlfriend', I don't want to give him an excuse like this. (Zora, 27)

\section{Conclusion}

Under the circumstance of commercial society, the emergence of various new Xiangqin forms has given rise to many socio-cultural changes on aspects of partner selection and marriage in China. The study argues that modern Chinese dating culture are symbolically and practically shaped by the commercial society. Apparently, the intersection between economics and people's intimate interactions perpetuates class divisions in current China. The commercialization of Xiangqin also reinforces traditional gender norms. Proactive men with wealth and young women attractive appearance occupy many resources on the marriage market; such social phenomenon also influences the design of many matchmaking activities and shapes the mating ideology of Chinese people. Nevertheless, commercialized Xiangqin also contributes to women empowerment at the same time. A dating culture penetrated by market value creates conditions for new Chinese femininity characterized by women's increased sense of autonomy, greater control over intimate relationship, and equality between the sexes.

\section{Reference}

Ahuvia, A. C., \& Adelman, M. B. (1993). Market metaphors for meeting mates. Research in Consumer Behavior, 6, 55-83.

Becker, G. S. (1973). A Theory of Mrriage: Part I. Journal of Political Economy, 82, 813-846.

Bernard/Ahuvia, A. C., Adelman, M. B., \& Schroeder, J. E. (1991). Two Views of Consumption in Mating and Dating. In R. H. Holman \& M. R. Solomon (Eds.), Advances in Consumer Research. Provo, UT: Association for Consumer Research.

Callsen, L. (2013). Timeline: A history of online dating Retrieved Apr 16, 2013, from http://metronews.ca/features/welcome-to-the-edating-jungle/544341/timeline-a-history-of-online-dating/

Constable, N. (2009). The Commodification of Intimacy: Marriage, Sex, and Reproductive Labor. Annual Review of Anthropology 38, 4964.

Coupland, J. (1996). Dating advertisements: Discourses of the commodified self. Discourse \& Society, 7, 187-207.

Edwards, J. N. (1969). Family Behavior as Social Exchange. Journal of Marriage and the Family, 31, 518-526.

Glosser, S. (2003). Chinese Visions of Family and State, 1915-1953, Asia-Local studies/global themes. Berkeley; London: University of California Press.

Heino, R. D., Ellison, N. B., \& Gibbs, J. L. (2010). Relationshopping: Investigating the market metaphor in online dating. Journal of Social and Personal Relationships, 27, 427-447.

Hirschman, E. (1987). People as Products: Analysis of a Complex Marketing Exchange. Journal of Marketing, 51, 98-108.

Illouz, E. (2007). Cold intimacies : the making of emotional capitalism. Cambridge: Polity Press.

Ip, H. Y. (2003). Fashioning appearances Feminine beauty in Chinese Communist revolutionary culture. Modern China(29), 329-361.

Jagger, E. (1998). Marketing the Self, Buying an other: Dating in a Post Modern,Consumer Society. Sociology, 32, 795-814.

Jagger, E. (2001). Marketing Molly and Melville: Dating in a Postmodern, Consumer Society. Society, 35(39-57).

Jing, J. H. (2011). TV dating shows under the perspective of feminism (Nvxing zhuyi shijiao xia de dianshi xiangqin jiemu). Southeast Communication(4), 62-64.

Lenton, A. P., Fasolo, B., \& Todd, P. M. (2010). Who Is in Your Shopping Cart? Expected and Experienced Effects of Choice Abundance in the Online Dating Context. In N. Kock (Ed.), Evolutionary psychology and information systems research: a new approach to studying the effects of modern technologies on human behavior (pp. 149-167). New York, N.Y. ; London Springer.

Li, B. (2011). Modern Dating Age: Functional TV Dating Shows. Retrieved Oct 29, 2011 www.artichokewebdesign.com I.../PDFs/Bing_Li_Dating_Shows.pdf

Li, B. (2011). Modern Dating Age: Functional TV Dating Shows. Retrieved Oct 29, 2011 www.artichokewebdesign.com I.../PDFs/Bing_Li_Dating_Shows.pdf

Li, C., \& Liu, P. Z. (2011). A brief discussion of current dating shows (Qiangtan dangxia "xiangqin jiemu"). Journalism \& Communication (1).

Millman, M. (1991). Warm Hearts and Cold Cash: The Intimate Dynamics of Families and Money. New York: The Free Press.

Takeuchi, S. (2006). On the Matching Phenomenon in Courtship: A Probability Matching Theory of Mate Selection. Marriage \& Family Review, 41(1), 25-51.

Yan, Y. X. (2010). The Chinese Path to Individualization. The British Journal of Sociology, 61(3), 489-512.

Zelizer, V. A. (1997). The Social Meaning of Money. Princeton, NJ: Princeton University Press.

Zelizer, V. A. (2005). The Purchase of Intimacy. Princeton, N. J.: Princeton University Press.

Zhao, Y. R. (2010). Stop being picky, says 'relationship expert Retrieved Oct, 27, 2011, from http://www.chinadaily.com.cn/metro/201003/26/content_9646491.htm 